\title{
Author Correction: Pairing of near-ultraviolet solar cells with electrochromic windows for smart management of the solar spectrum
}

Nicholas C. Davy¹, Melda Sezen-Edmonds¹, Jia Gao¹, Xin Lin², Amy Liu¹, Nan Yao³, Antoine Kahn² and Yueh-Lin Loo ${ }^{1,4 \star}$

Nature Energy 2, 17104 (2017); published online 30 June 2017; corrected online 18 September 2017.

In the version of this Article originally published, Fig. $4 \mathrm{f}$ was incorrect. This error has now been corrected (see new figure below).
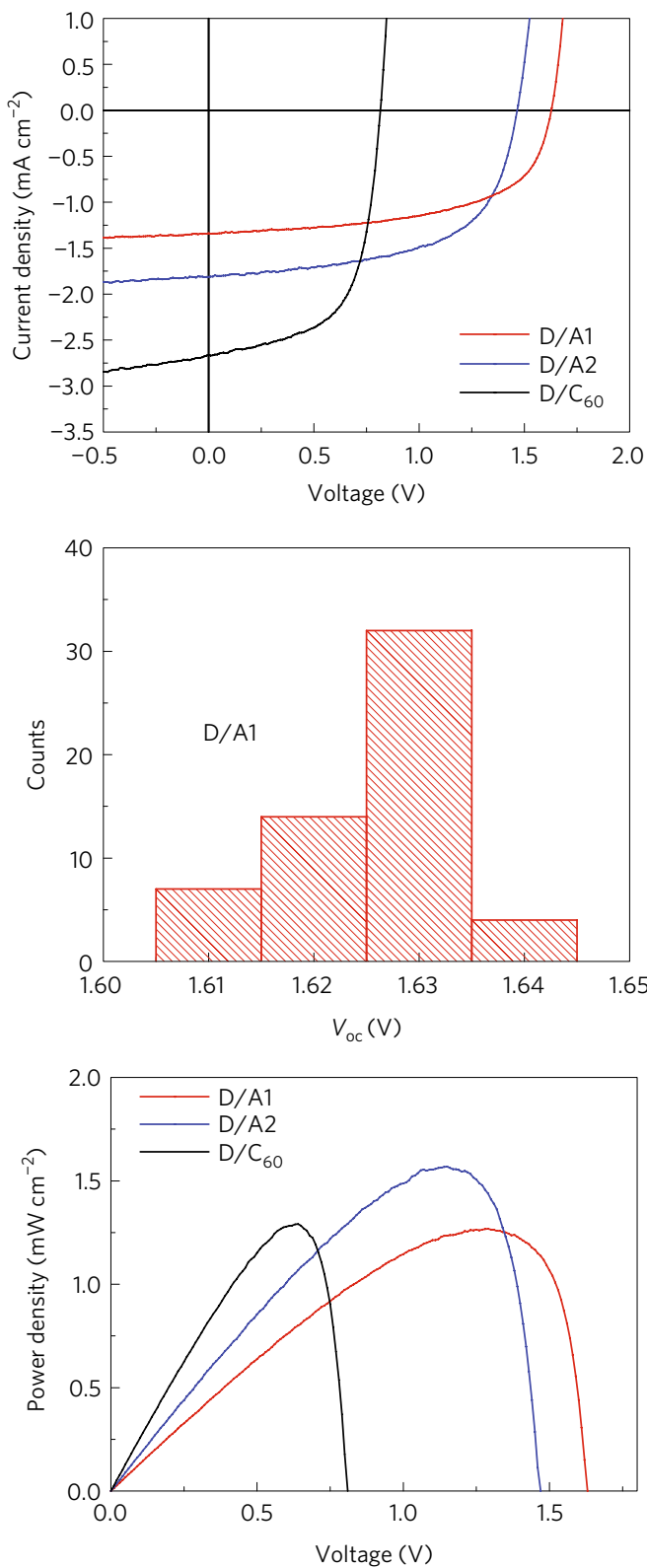

b

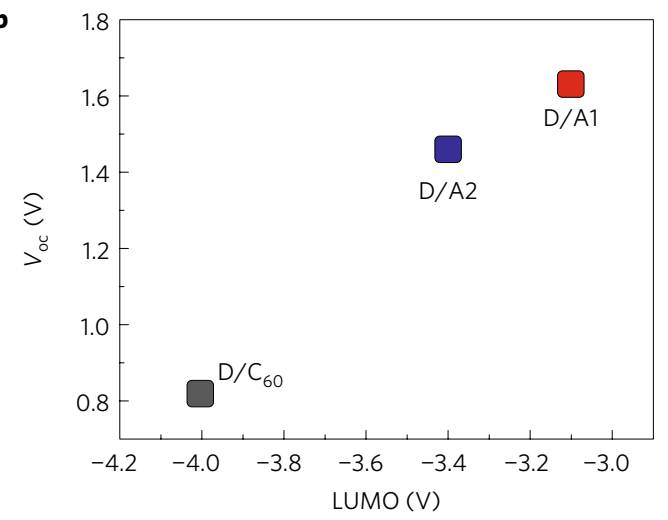

d

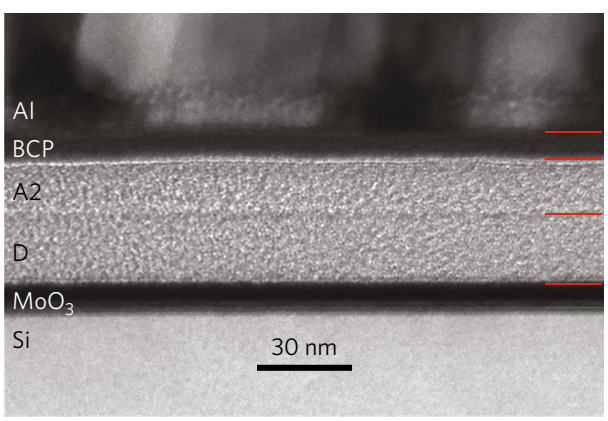

$\mathbf{f}$

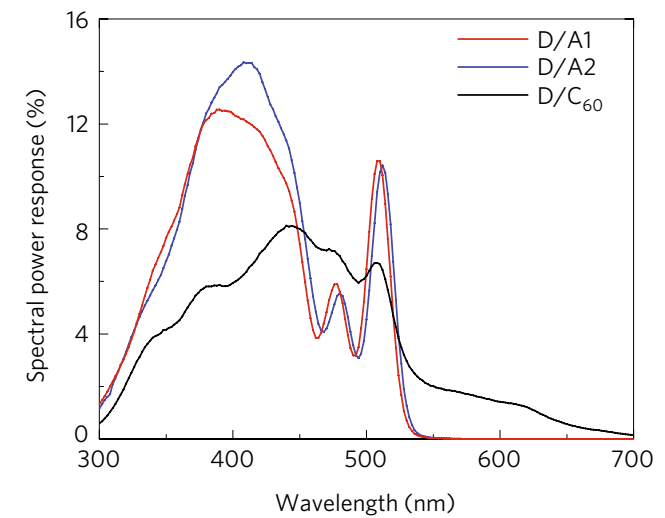

